\title{
Verbal Autopsy of Stillbirths and Neonatal Deaths in a Rural Area of Burkina Faso
}

\author{
Fla Koueta ${ }^{1,2,3}$, Kisito Nagalo1,2,4*, Leatitia Ouedraogo², François Housseini Tall1, \\ Diarra Ye1,2,3 \\ ${ }^{1}$ The Burkinabe Pediatrics Society, Ouagadougou, Burkina Faso \\ ${ }^{2}$ Training and Research Unit of Health Sciences, University of Ouagadougou, Ouagadougou, Burkina Faso \\ ${ }^{3}$ Service of Medical Pediatrics, Charles De Gaulle Pediatric University Teaching Hospital, Ouagadougou, Burkina Faso \\ ${ }^{4}$ Service of Pediatrics, Clinique El Fateh-Suka, Ouagadougou, Burkina Faso \\ Email: kiki nagalo@yahoo.fr
}

Received 27 April 2015; accepted 4 June 2015; published 8 June 2015

Copyright (C) 2015 by authors and Scientific Research Publishing Inc.

This work is licensed under the Creative Commons Attribution International License (CC BY). http://creativecommons.org/licenses/by/4.0/

(c) (i) Open Access

\begin{abstract}
Introduction: In developing countries, many neonatal deaths still occur at home and the causes of these deaths are not ascertained. Objective: To identify the causes of stillbirths and neonatal deaths that occur at home and the factors that have contributed to these deaths. Materials and Method: We have used the method of verbal autopsy to investigate the stillbirths and neonatal deaths in nine villages in the health area of Namsiguia, health district of Ouahigouya, Burkina Faso, during the period January 1, 2007 to December 8, 2012. Results: Over these six years, we have recorded 19 stillbirths and 36 neonatal deaths among 1507 live births, demonstrating a neonatal mortality rate of 28.8 per1000 and a rate of stillbirths of 12.6 per 1000 . The average age of newborns at death was 5.6 days and the sex-ratio was 1.6. The major cause of stillbirths was antenatal hypoxia and birth asphyxia $(42.1 \%)$. The direct causes of neonatal deaths were neonatal sepsis (41.7\%), preterm birth (19.4\%) and hypoxia and birth asphyxia (11.1\%). There were $42.1 \%$ deliveries and $58.3 \%$ neonatal deaths, which occurred at home. We have noted $89.5 \%$ fresh stillbirths. Death occurred more often during the early neonatal period (55.5\%). Factors significantly associated with neonatal death were, lack of school education of mothers $(\mathrm{OR}=4)$, precocious marriage of the mother $(O R=8)$, poor follow-up of pregnancies $(O R=3)$, birth at home $(O R=4)$, low socioeconomic level $(O R=6)$, and low geographical access to the health facility $(O R=4)$. Conclusions: Strengthening of the health infrastructure and improving their accessibility, reinforcement of the staff for high quality care, and communication for a change in behavior in rural communities, will contribute toward reducing neonatal mortality in the area of health of Namsiguia.
\end{abstract}

\section{Keywords}

Verbal Autopsy, Neonatal Deaths, Stillbirths, Cause of Death

\footnotetext{
${ }^{*}$ Corresponding author.
}

How to cite this paper: Koueta, F., Nagalo, K., Ouedraogo, L., Tall, F.H. and Ye, D. (2015) Verbal Autopsy of Stillbirths and Neonatal Deaths in a Rural Area of Burkina Faso. Open Journal of Pediatrics, 5, 164-170. 


\section{Introduction}

Of the 130 million annual births worldwide, there are approximately four million neonatal deaths, an equivalent of stillbirths is counted, and more than $98 \%$ of these deaths occur in developing countries [1]-[3]. Furthermore, most of these neonatal deaths occur at the community level and are, therefore, not recorded and their exact causes not elucidated. Verbal autopsy is a method that aims to identify the causes and factors that contribute to these deaths when they occur outside a health facility [4]. This method is an alternative to medical audit, in the context of low accessibility to health services, in order to determine the avoidable factors of death and take appropriate corrective measures. It is, therefore, particularly suitable for poor countries like Burkina Faso, where the neonatal mortality rate is estimated at 28 per 1000 , where more than $77 \%$ of the population live in rural areas, and where $45 \%$ live under the threshold of poverty, with a low attendance of health services [3]. This verbal autopsy, which was carried out in a rural area was designed to determine the causes of stillbirths and neonatal deaths, as well as the factors leading to the deaths. Taking account of the identified modifiable factors should enable the reduction of neonatal mortality and contribute to the achievement of the Fourth Millennium Development Goal (MDG4), whose target is to reduce the under-five mortality rate by two-thirds, by 2015.

\section{Materials and Method}

\subsection{Setting}

The study was carried out in the rural area of the health and social promotion center (CSPS) of Namsiguia. The CSPS depends on the health district of Ouahigouya, which is a town located $200 \mathrm{~km}$ north off Ouagadougou, the capital of Burkina Faso. The infrastructure of the CSPS included a dispensary, a repository of essential generic medicines and a maternity ward, which was under construction. The CSPS team comprised of two nurses and an auxiliary midwife. Two community health workers served as community relays. The CSPS covered nine villages, with a population estimated at approximately 9000 inhabitants. Accessibility to the CSPS was difficult during the rainy season owing to flooding in the lowland situated between the villages and the health center.

\subsection{Method and Study Population}

A descriptive and analytic study allowed inclusion of all cases of stillbirths and neonatal deaths that occurred in the health area of the CSPS of Namsiguia between January 2007 and December 2012, or a six year period. The method of the verbal autopsy was used. A proforma, adapted by the World Health Organization (WHO) standard No. 1 questionnaire of verbal autopsy, was designed for this study [5]. The interview respondents were the mother and/or the father of the stillborn or deceased newborn. Close family members who were present at the time of the death were also interviewed.

\subsection{Data Collection and Management}

Data collection unwound from February 1 to March 31, 2014. The main technique of data collection was a direct interview with individual or collective respondents, with their consent. If necessary, this technique was complemented by the review of files and records of the patients at the CSPS or at the regional hospital. Four health personnel and six investigators, who conducted the data collection, had been previously trained on the verbal autopsy technique and filling investigation proforma. The questionnaire was pretested, which allowed its revision. Births and neonatal deaths were identified before the beginning of the investigation by the two community health workers, who were well informed of these events in the villages. This allowed the investigators to go directly to the families where the death took place. Two doctors insured the supervision of the survey. After collection of the data, the audit was conducted by a team consisting of two pediatricians, two medical practitioners, and a nurse during a staff meeting. This allowed determination of the direct and indirect causes of the deaths and identified the factors associated with these deaths. Each sheet was reviewed and the causes of the death were set, depending on the algorithm used by Manandhar et al. [6]. A single cause of death and stillbirth was assigned per child. Causes of neonatal deaths were classified using the international classification of diseases of the WHO, tenth edition (ICD 10) [7]. The socioeconomic level of the surveyed family was classified as low, medium or high, according to the WHO classification [8]. To find the existence of a statistical significance associated with the studied factors, each deceased newborn was matched to a control, who was a living newborn. The matching 
was made on date of birth, sex, and the village of birth of the deceased infants, with a ratio equal to 1 . The matching on the date of birth was obtained more or less to a 15-day extent. Data were entered using the Sphin $\mathrm{x}^{\mathrm{TM}}$ version 5 software (the Sphinx development, 27, rue Cassiopée, Parc Atlais, Chavanod, France) and then analyzed using SPSS 16.0 (IBM SPSS Inc., Chicago, Illinois, USA). Chi-square and Fisher's tests were used for comparisons between proportions. The odds ratio (OR) was computed to determine the significance of the association between variables, and the 95\% confidence interval (CI) was calculated. Statistical tests yielding $p$-values $<0.05$ were considered significant.

\subsection{Ethical Considerations}

During the preparatory phase of the investigation, we first obtained permission from the Ministry of Health. Furthermore, during a seminar, the community leaders (heads customary and religious, village development advisers) and the administrative authorities (mayor, prefect) of the study area were informed and sensitized on the verbal autopsy of neonatal deaths and its objectives. Populations that were the subject of the study were also informed on the project of study and it was with their consent that we conducted this investigation.

\section{Results}

\subsection{Frequency of Stillbirths and Neonatal Deaths}

Over the period of the study, a total of 55 stillbirths and neonatal deaths were identified consisting of 19 stillbirths and 36 neonatal deaths. During the same period, 1507 births were identified, demonstrating a rate of stillbirth of 12.6 per 1000 and a neonatal mortality rate of 28.8 per 1000 . The state of stillbirths was specified in 16 cases and fresh stillbirths were 14 (87.5\%), the other two (12.5\%) were macerated stillborns. The sex ratio of the deceased newborns was 1.6 and the average age at death was 5.6 days.

\subsection{Causes of Stillbirths and Neonatal Deaths}

The direct causes of stillbirths were antenatal hypoxia and asphyxia at birth (eight cases), preterm birth (one case), and low birth weight (one case). The indirect causes found were related to maternal illness during pregnancy consisting of malaria (five cases), anemia (three cases), and hypertension (one case). The main direct causes of neonatal deaths were sepsis (41.7\%), preterm birth (19.4\%), and antenatal hypoxia and asphyxia at birth (11.1\%). Sepsis was the most common cause of death in the late neonatal period (75.0\%), whereas, antenatal hypoxia and asphyxia at birth (20.0\%) and preterm birth (25.0\%) were the most common causes of death in the early neonatal period, as shown in Table 1.

The indirect causes of neonatal deaths were maternal causes that were found in 19 cases out of 36 (52.8\%). It was sepsis in 13 cases (68.5\%) of which nine cases were of fever of unknown origin, three cases were of possible urinary tract infection, and one case was of malaria. Hypertension, prolonged labor, and anemia (two cases each) were the other maternal causes of neonatal deaths.

Table 1. Distribution of neonatal deaths by cause and timing of death, Namsiguia, Burkina Faso, 2012.

\begin{tabular}{cccc}
\hline \multirow{2}{*}{ Cause of death } & \multicolumn{1}{c}{ Timing of death } & Total \\
\cline { 2 - 4 } & $\begin{array}{c}\text { ENNP }^{*} \\
\text { No. of deaths (\%) }\end{array}$ & $\begin{array}{c}\text { LNNP }^{\dagger} \\
\text { No. of deaths (\%) }\end{array}$ & No. of deaths (\%) \\
\hline Neonatal sepsis & $3(15.0)$ & $12(75.0)$ & $7(19.4)$ \\
Preterm birth & $5(25.0)$ & $2(12.5)$ & $4(11.1)$ \\
Birth asphyxia & $4(20.0)$ & $0(0.0)$ & $1(2.8)$ \\
Congenital anomalies & $0(0.0)$ & $1(6.25)$ & $9(25.0)$ \\
Unspecified & $8(40.0)$ & $1(6.25)$ & $36(100.0)$ \\
\hline
\end{tabular}

*ENNP: Early Neonatal Period (0 - 6 days); ${ }^{\dagger}$ LNNP: Late Neonatal Period (7 - 28 days). 
Table 2. Factors associated with neonatal deaths, Namsiguia, Burkina Faso, 2012.

\begin{tabular}{|c|c|c|c|c|}
\hline \multirow[t]{2}{*}{ Putative risk factor for death } & \multicolumn{4}{|c|}{ Newborn } \\
\hline & Deceased $(n=36)$ & Alive $(n=36)$ & OR $[95 \% \mathrm{CI}]^{*}$ & p-value \\
\hline \multicolumn{5}{|l|}{ Lack of maternal education } \\
\hline Yes & 30 & 20 & $4[1.2-13.9]$ & 0.01 \\
\hline No & 6 & 16 & 1.0 & \\
\hline \multicolumn{5}{|c|}{ Precocious marriage (mother $<18$ years) } \\
\hline Yes & 25 & 8 & $8[2.8-22.9]$ & 0.00006 \\
\hline No & 11 & 28 & 1.0 & \\
\hline \multicolumn{5}{|l|}{ Large multiparous mother ( $>=5$ para) } \\
\hline Yes & 9 & 3 & $4[0.8-2.0]$ & 0.5 \\
\hline No & 27 & 33 & 1.0 & \\
\hline \multicolumn{5}{|c|}{ Poor follow-up of pregnancy (No. of $\mathrm{ANC}^{\dagger} \mathrm{s}<3$ ) } \\
\hline Yes & 16 & 7 & $3[1.0$ - 10.9] & 0.02 \\
\hline No & 20 & 29 & 1.0 & \\
\hline \multicolumn{5}{|l|}{ Birth at home } \\
\hline Yes & 15 & 5 & $4[1.2-16.6]$ & 0.01 \\
\hline No & 21 & 31 & 1.0 & \\
\hline \multicolumn{5}{|l|}{ Socioeconomic level of parents } \\
\hline Low & 32 & 20 & $6[1.7-26.8]$ & 0.001 \\
\hline Medium & 4 & 16 & 1.0 & \\
\hline \multicolumn{5}{|c|}{ Lack of geographical access to the health center } \\
\hline Yes & 30 & 20 & $4[1.2-13.9]$ & 0.01 \\
\hline No & 6 & 16 & 1.0 & \\
\hline
\end{tabular}

*Odds ratio [95\% Confident interval]; ${ }^{\dagger}$ Antenatal cares.

\subsection{Factors Related to Neonatal Deaths}

Deaths were early (55.5\%) and more often occurred at home (58.3\%). Factors significantly associated with neonatal deaths were, lack of maternal education $(\mathrm{OR}=4)$, precocious marriage $(\mathrm{OR}=8)$, poor follow-up of pregnancies $(\mathrm{OR}=3)$, birth at home $(\mathrm{OR}=4)$, low socioeconomic level $(\mathrm{OR}=6)$, and lack of geographical access to the health center $(\mathrm{OR}=4)$ (Table 2).

\section{Discussion}

Verbal autopsy aims at reduction of mortality. When it is implemented as a participatory process in a community, it can provide awareness of the factors that lead to deaths and can stimulate collective action. Despite the memory potential bias, owing to the retrospective collection of painful memories, questioning the mothers allowed us to obtain sufficient reliable information about stillbirths and neonatal deaths, which we have compared with data from the literature.

\subsection{Stillbirths}

With 12.6 per1000, the rate of stillbirths in our study was lower than the national rate, which is estimated to be 26 per 1000 [9]. This lower rate in our study is probably because of the small size of our sample, in a well-circumscribed health area, while the national rate is global and masks the disparity between regions. Antenatal hypoxia and asphyxia at birth were the main causes of stillbirths in this study. The discovery of a fresh stillbirth suggests that the child was viable during labor [6] and death dates back to less than 12 hours before birth [10]. In this study, as in those of other authors from countries with limited resources [11]-[13], the observed proportions of fresh stillbirths may reflect that women in labor had a delay in receiving care or there was lack of monitoring of the delivery by the care providers. This low capacity of the health care centers to provide quality rural perinatal care in Burkina Faso was already noted by Nikiema et al. [14], in the North East of the country. This high level of stillbirths is compounded by the fact that there are no skilled care providers in the community to take over deliveries or give neonatal care at home in accordance with our current national health policy. However, 
according to several authors, community health workers do exist, who are trained to recognize the signs of danger and practice basic neonatal resuscitation to reduce deaths from asphyxia during labor [6] [15] [16].

\subsection{Neonatal Deaths}

The rate of 28.8 per 1000 of neonatal mortality in this study is comparable to the national neonatal mortality of 28 per 1000 [3]. Neonatal mortality remains a factor of worry in our country despite the efforts of giving a grant for obstetric and neonatal emergency care [17]. The causes of neonatal deaths were dominated by neonatal sepsis $(41.7 \%)$ in this study and these deaths by sepsis were most frequent in the late neonatal period (75\%). The high rate of deaths by sepsis after the first week was especially on account of the many deliveries that took place at home, which occurred in poor conditions of hygiene and traditional practices, harmful to the health of the newborn child during the section and the care of umbilical cord. These poor conditions of delivery and umbilical cord care had already been reported by Bagui et al. in India [11] and Manandhar et al. in the Nepal [6]. To reduce neonatal sepsis, awareness messages should be addressed to women and their families, to encourage deliveries at the health center and to abandon the traditional practices harmful to the health of the newborn.

This study has identified preterm birth (19.4\%) as the second cause of neonatal death. Sombie [18] in the West of Burkina Faso, Edmond et al. [13] in Ghana, and Turnbull et al. [12] in Zambia had made the same observation, with the respective preterm death rates of $15 \%, 19.7 \%$, and $34 \%$. Poverty, hardship of field work and chores, the long walks on foot to look for firewood and water are situations experienced daily by women in the area of this study, which encourage preterm deliveries. In this study, preterm deaths were mainly related to the inadequacy of their management in a health center, however precarious this may be in a rural area of a developing country like Burkina Faso. However, the implementation of low-cost methods that have proven their effectiveness and that are adopted by poor countries, such as the Kangaroo method, can reduce neonatal mortality linked to preterm birth and low birth weight [19]. Actions that are aimed at improving the social economic status of women in developing countries, as well as the promotion of essential neonatal care in the context of a community health policy will reduce preterm-related morbidity and neonatal mortality.

Antenatal hypoxia and asphyxia at birth was the third cause of neonatal deaths in our study with a mortality rate of $11.1 \%$; which is three times lesser than in the study of Manandhar et al. [6] in the Nepal and Edmond et al. [13] in Ghana. In sub-Saharan Africa, asphyxia at birth is responsible for 280,000 deaths per year, especially on the first day of life [9]. Poor quality of care, inadequate fetal monitoring, and lack of skills of the health personnel are frequently associated with asphyxia at birth [20]. The training and equipment of community health workers for basic neonatal resuscitation can combat neonatal asphyxia and death which are linked [6] [16].

\subsection{Factors Associated with Neonatal Deaths}

The occurrence of the death of a newborn is often the result of several factors, some of which are preventable. In this study, the factors associated with neonatal deaths were the social, cultural, economic, and environmental factors. The analysis of these factors allows us to classify them in three delays according to the conceptual model proposed by Thaddeus [21] and used by other authors [22] [23] to trace the path that leads to the death of a newborn. The first delay is relative to the decision to go to a health facility. It follows from a persistence of the harmful social cultural constraints to health, lack of knowledge of the signs of danger, and the weakness of the decision-making power of the woman, who is yet the center of care of the children. In this study the risk of neonatal death was multiplied four times in the absence of mother's school education, five times in the event of precocious marriage, three times if pregnancy was poorly followed, and four times in the event of delivering at home. The second delay deals with access to the health facility. In this study, the risk of death was significantly associated with lack of geographical access to the health center $(\mathrm{OR}=4)$ and the low socioeconomic level of parents $(\mathrm{OR}=6)$. The third delay relates to the quality of care received once the newborn arrives in the health center. In this study, we observed the failing in the care of the newborn and the ignorance of pregnancies at risk by the health personnel. Beyond the social cultural constraints, delays seem to be interdependent. Indeed, going by the challenges for the transport and the cost of care in health facilities, the population often resigns to stay at home, abandoning themselves to fatalism. With the optimal implementation of a subsidy policy of obstetric and neonatal care emergency care, which has begun in Burkina Faso, since 2006, in particular in its section on transport and medical care, it is expected to accelerate the reduction of neonatal mortality. 


\section{Conclusion}

Verbal autopsy permitted the identification of preventable causes of stillbirths and neonatal deaths in the health area of Namsiguia, Burkina Faso. The associated factors, in particular, were economic and social cultural. Improving school education, especially for women, reduction of extreme poverty, improvement of accessibility to high quality health services, promotion of essential newborn care, and adoption and implementation of a community health policy are essential for the reduction in neonatal mortality and for improving newborn survival in Burkina Faso, especially in the rural area.

\section{Acknowledgements}

The authors thank the staff of the Regional Directorate of Health of the North and the Regional Directorate of the Health District of Ouahigouya. They express their gratitude to the members of the bereaved families who have accepted to talk about an event as painful as the loss of one of their own.

\section{Funding}

This study was conducted with financial support from the West African Health Organization (WAHO), BoboDioulasso, Burkina Faso.

\section{References}

[1] Lawn, J.E., Cousens, S., Bhutta, J.A., Darmstadt, G.L., Martines, J., Pual, V., et al. (2005) 4 Millions Neonatal Deaths: When? Where? Why? The Lancet, 365, 891-900. http://dx.doi.org/10.1016/S0140-6736(05)71048-5

[2] Labie, D. (2005) Le scandale des 4 millions de morts néonatales chaque année: Bilan et actions possibles. Médecine/Sciences, 21, 768-771. http://dx.doi.org/10.1051/medsci/2005218-9768

[3] Institut national de la statistique et de la démographie (Burkina Faso) (2010) Enquête Démographique et de Santé et à Indicateurs Multiples (EDSBF-MICS IV). http://www.insd.bf

[4] Patel, Z., Kumar, V., Singh, P., Singh, V., Yadav, R., Baqui, A.H., et al. (2007) Feasibility of Community Neonatal Death Audits in Rural Uttar Pradesh, India. Journal of Perinatology, 27, 556-564. http://dx.doi.org/10.1038/sj.jp.7211788

[5] WHO (2012) Verbal Autopsy Standards: 2012 WHO Verbal Autopsy Instrument. http://www.who.int/healthinfo/statistics/WHO_VA_2012_RC1_Instrument.pdf?ua=1

[6] Manandhar, S., Ojha, A., Manandhar, D.S., Shrestha, B., Shrestha, D., Saville, N., et al. (2010) Causes of Stillbirths and Neonatal Deaths in Dhanusha District, Nepal: A Verbal Autopsy Study. Kathmandu University Medical Journal, 29, 62-72. http://dx.doi.org/10.3126/kumj.v8i1.3224

[7] WHO (2012) International Statistical Classification of Diseases and Related Health Problems 10th Revision. http://apps.who.int/classifications/icd10/browse/2010/en

[8] Yach, D., Mathews, A.C. and Buch, E. (1990) Urbanisation and Health: Methodological Difficulties in Undertaking Epidemiological Research in Developing Countries. Social Science \& Medicine, 31, 507-514. http://dx.doi.org/10.1016/0277-9536(90)90047-V

[9] Lawn, J. and Kerber, K. (2006) Opportunities for Africa’s Newborns: Practical Data, Policy and Programmatic Support for Newborn Care in Africa. PMNCH, Cape Town. http://www.who.int/pmnch/media/publications/opportunitiesfr.pdf

[10] Lawn, J., Shibuya, K. and Stein, C. (2005) No Cry at Birth: Global Estimates of Intrapartum Stillbirths and Intrapartum-Related Neonatal Deaths. Bulletin of the World Health Organization, 83, 409-417.

[11] Baqui, A.H., Darmstadt, G.L., Williams, E.K., Kumar, V., Kiran, T.U., Panwar, D., et al. (2006) Rates, Timing and Causes of Neonatal Deaths in Rural India: Implications for Neonatal Health Programs. Bulletin of the World Health Organization, 84, 706-713. http://dx.doi.org/10.2471/BLT.05.026443

[12] Turnbull, E., Lembalemba, M.K., Guffey, M.B., Bolton-Moore, C., Mubiana-Mbewe, M., Chintu, N., et al. (2011) Causes of Stillbirth, Neonatal Death and Early Childhood Death in Rural Zambia by Verbal Autopsy Assessments. Tropical Medicine \& International Health, 16, 894-901. http://dx.doi.org/10.1111/j.1365-3156.2011.02776.x

[13] Edmond, K.M., Quigley, M.A., Zandoh, C., Danso, S., Hurt, C., Agyei, S.O., et al. (2008) Aetiology of Stillbirths and Early Neonatal Deaths in Rural Ghana: Implications for Health Programming in Developing Countries. Paediatric and Perinatal Epidemiology, 22, 430-437. http://dx.doi.org/10.1111/j.1365-3016.2008.00961.X

[14] Nikiema, L., Kameli, Y., Capon, G., Sondo, B. and Martin-Prevel, Y. (2010) Quality of Antenatal Care and Obstetrical Coverage in Rural Burkina Faso. Journal of Health, Population and Nutrition, 28, 67-75. 
http://dx.doi.org/10.3329/jhpn.v28i1.4525

[15] Carlo, W.A., Goudar, S.S., Jehan, I., Chomba, E., Tshefu, A., Garces, A., et al. (2010) Newborn-Care Training and Perinatal Mortality in Developing Countries. New England Journal of Medicine, 362, 614-623. http://dx.doi.org/10.1056/NEJMsa0806033

[16] Sangho, H., Doumbia, S., Dembélé-Kéïta, H., Sidibé-Kéïta, A., Coulibaly, L., Diakité, B., et al. (2010) Intervention Communautaire Pour réduire au Mali la mortalité néonatale due à l'asphyxie. Sante Publique, 22, 471-479.

[17] Ministère de la santé (Burkina Faso) (2006) Plan d'accélération de réduction de la mortalité maternelle et néonatale au Burkina Faso (Feuille de Route). Direction de la Santé de la Famille, Ouagadougou. http://www.unfpa.org/sowmy/resources/docs/library/R061_MOHBURKINAFASO_2006_Plan_daccelerationMMR_O ctobre_2006.pdf

[18] Sombié, I. (2002) Mortalité néonatale et maternelle en milieu rural au Burkina Faso. Université Libre de Bruxelles, Bruxelles. http://www.memoireonline.com/a/fr/cart/download/t4mBNXRPO8Z8

[19] Lawn, J.E., Mwansa-Kambafwile, J., Horta, B.L., Barros, F.C. and Cousens, S. (2010) "Kangaroo Mother Care” to Prevent Neonatal Deaths Due to Preterm Birth Complications. International Journal of Epidemiology, 39, i144-i154. http://dx.doi.org/10.1093/ije/dyq03

[20] Andreasen, S., Backe, B. and Oian, P. (2013) Claims for Compensation after Alleged Birth Asphyxia: A Nationwide Study Covering 15 Years. Acta Obstetricia et Gynecologia Scandinavia, 93, 152-158.

[21] Thaddeus, S. and Maine, D. (1994) Too Far to Walk: Maternal Mortality in Context. Social Science \& Medicine, 38, 1091-1110. http://dx.doi.org/10.1016/0277-9536(94)90226-7

[22] Waiswa, P., Kallander, K., Peterson, S., Tomson, G. and Pariyo, G.W. (2010) Using the Three Delays Model to Understand Why Newborn Babies Die in Eastern Uganda. Tropical Medicine \& International Health, 15, 964-972. http://dx.doi.org/10.1111/j.1365-3156.2010.02557.x

[23] Kouéta, F., Yugbaré-Ouédraogo, S.O., Dao, L., Dao, F., Yé, D. and Kam, K.L. (2011) Audit médical des décès néonatals selon le modèle des trois retards, en milieu hospitalier pédiatrique de Ouagadougou. Santé, 21, 209-214. 